\title{
Electrochemotherapy on Bladder - Preliminary Results
}

\author{
Marcelo Monte Mor Rangel ${ }^{1}$, Krishna Duro de Oliveira ${ }^{1}$, Jennifer Ostrand Freytag ${ }^{1}$, Priscila Gil Quadros ${ }^{1}$ and $^{2}$ \\ Daniela Ota Hisayasu Suzuki*2
}

${ }^{1}$ Vet Câncer Clinic, Brazil

${ }^{2}$ Biomedical engineering institute, Brazil

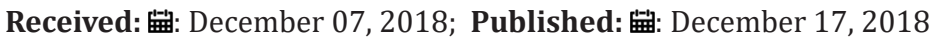

*Corresponding author: Daniela Ota Hisayasu Suzuki, Biomedical engineering institute, Brazil

\section{Introduction}

Electrochemotherapy is a technique that associates electropermabilization with the administration of low permeant or non-membrane permeant drugs to membranes [1-3]. The two main drugs used are bleomycin and cisplatin [4,5]. When bleomycin is used, an interesting selectivity to the neoplastic tissue is observed. This is because bleomycin mainly acts on cells that are dividing [6-8]. Bladder cancer in dogs represent about $2 \%$ of all neoplasms and usually when diagnosed are staged T2 or T3. More than $50 \%$ is in the trigone and this limits the surgical approach. Chemotherapy is considered the main approach for these reasons [9]. As electrochemotherapy has this selective characteristic to the neoplastic tissue, the hypothesis of this approach is to perform the technique directly on the bladder, by cystotomy, to achieve complete remission of the tumor, without major functional damages to urinary lower tract.

\section{Case Presentation}

Two patients, a pug 8 years and a Poodle 13, showing bladder cancer located on the trigone (Figures 1 \& 2), were referred to undergo cystotomy procedure to perform Electrochemotherapy on the bladder. The exclusion criteria established to applying the technique were the fact that the patients were not able to undergo general anesthesia, having staging T3 and the presence of neoplasia in the serous layer of the bladder. In each procedure, histological evaluation was performed intraoperatively for diagnosis of the neoplasm and evaluation of the infiltration level in the layers of the bladder wall. The electropermabilization protocol used was 1300 $\mathrm{V} / \mathrm{cm}, 100 \mu \mathrm{s}$ pulse duration, $5 \mathrm{KHz}$ frequency and 8 pulses. The drug used was bleomycin, intravenous, $15,000 \mathrm{IU} / \mathrm{m}^{2}[4,6,7,10,11]$. Electropermalization was performed 8 minutes after intravenous administration of the drug [11]. The plan after the first procedure would be to perform a posterior cystotomy, within about 30 days, for inspection of the histological evaluation in the intraoperative period, to identify the presence or not of tumor. In case of presence of tumor, electrochemotherapy would be performed again immediately.

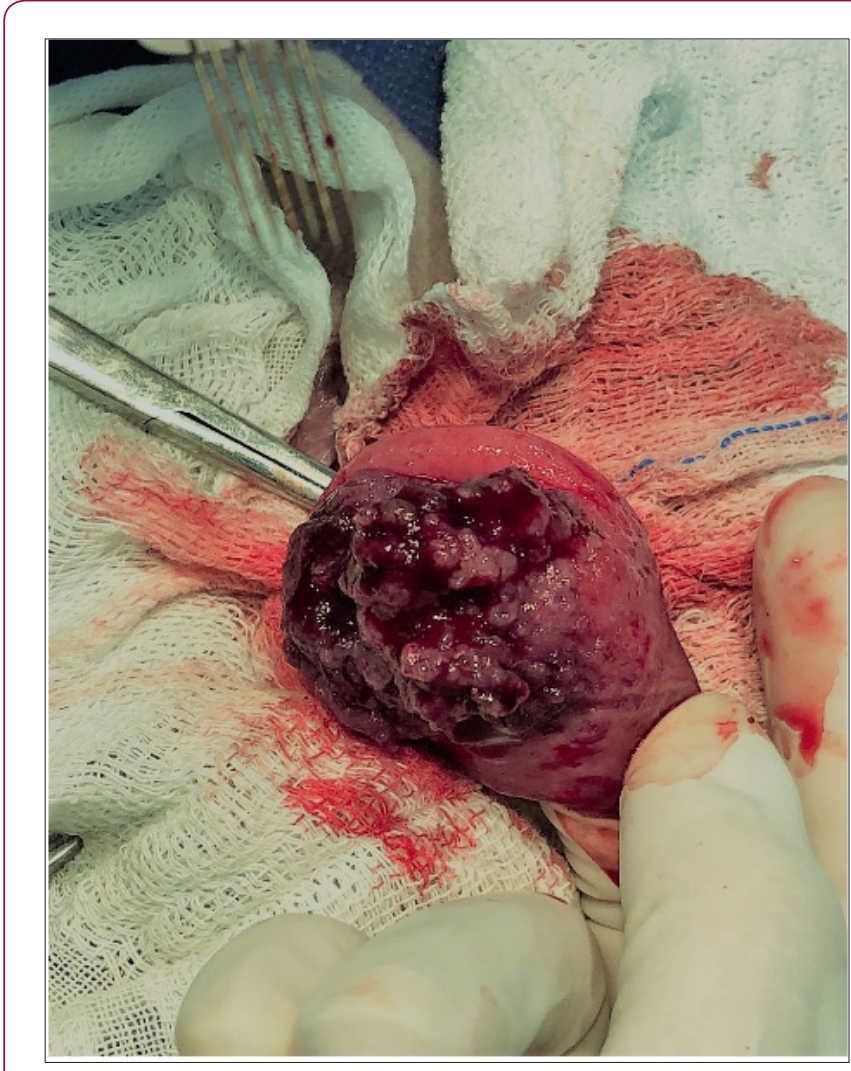

Figure 1: Bladder with Transitional cell carcinoma involvement on trigone. 


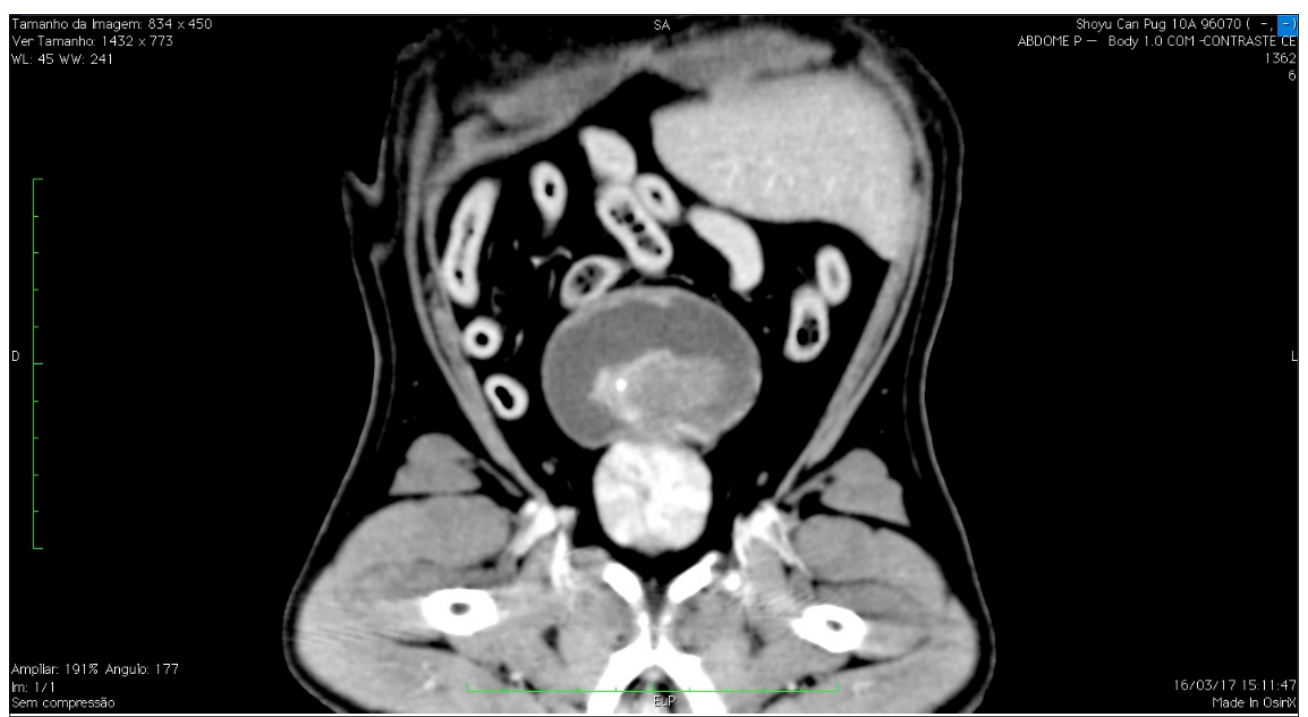

Figure 2: Computed Tomography showing trigone involved by transitional cell carcinoma.

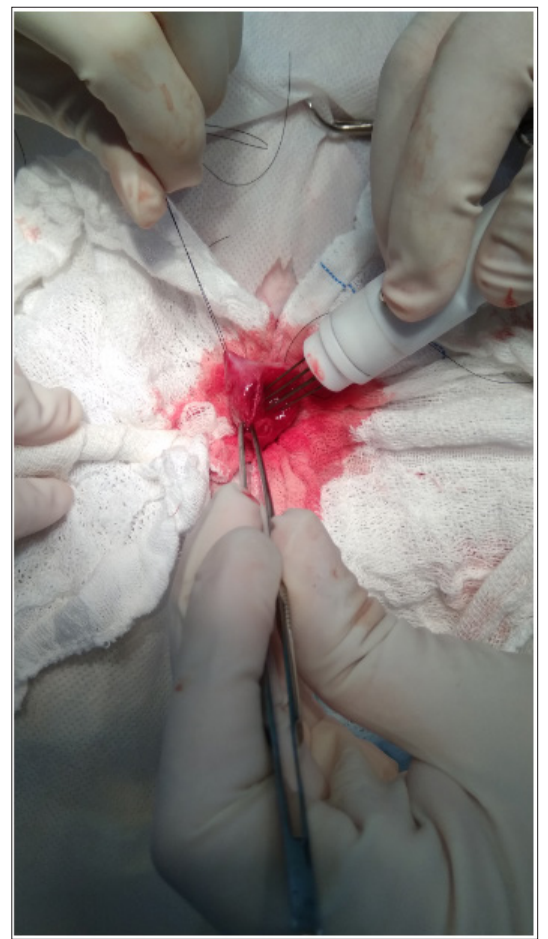

Figure 3: Electrochemotherapy being performed directly on the bladder.

Before the first procedure staging tests were performed, chest X-ray, abdomen and Ultrasonography (US), pre-surgical examination, echocardiography, complete blood count, BUN, creatinine, ALT, alkaline phosphatase. Both patients presented alteration only in the US of abdomen, with presence of mass in region of trigone. Both patients underwent three surgical procedures. In the first procedure the diagnosis of transitional cell carcinoma was made in the transoperative and electrochemotherapy was immediately performed on the bladder (Figure 3). In the second procedure, performed 25 and 32 days respectively later, in both patients, necrosis on the treated area were observed (Figure 4). During the second procedure, histopathology analysis by frozen section, provided confirmation of tumor evidence and new electrochemotherapy was performed immediately. In the third procedure, performed 70 days after the first one, a new histopathologic sample was collected and in one of the patients, the tumor was not present, in the other only microscopic evidence was found (Figure 5). In both cases, a new electrochemotherapy session was performed. After the three procedures, both patients underwent 6 sessions of carboplatin, $300 \mathrm{mg} / \mathrm{m}^{2}$ every 21 days. After 6 sessions of chemotherapy, new staging tests were performed (RX chest and abdomen US) and no change was found. There was no evidence of tumor in the ultrasonography images of the bladder.

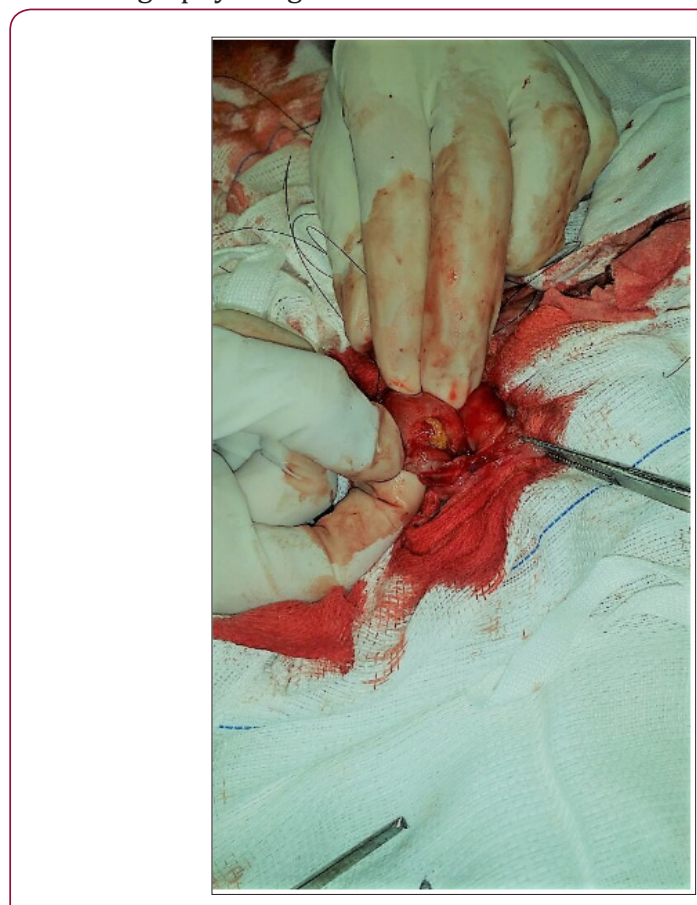

Figure 4: Evidence of necrosis on treated area by electrochemotherapy. 


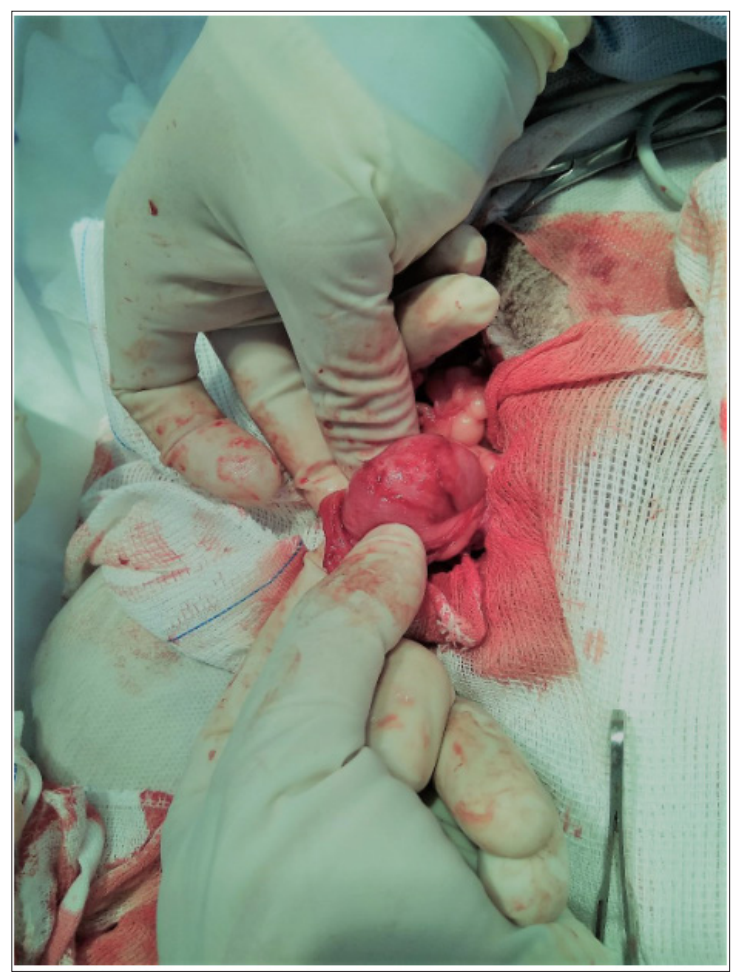

Figure 5: Bladder with no clinical evidence of tumor after 2 electrochemotherapies 70 days after the first one application.

\section{Results}

Both patients presented complete remission after the two electrochemotherapy procedures. One patient had only microscopic evidence of disease. The third procedure was performed in both for safety since the result of intraoperative histological evaluation is sampling. Both patients had temporary urinary incontinence. Complete resolution of urinary incontinence occurred 76 and 56 days respectively after the third procedure. No other side effects were observed after all three procedures. Patients today are free of the disease for 657 and 615 days respectively and with no evident clinical change.

\section{Discussion}

Chemotherapy is considered the main treatment of bladder cancer [9,12]. With this approach the median survival may exceed beyond one year, and the main response that is expected is the stabilization of the disease with the patient undergoing chemotherapy for the rest of its life [9]. The purpose of the electrochemotherapy on bladder is that the patient achieves complete remission of tumor, and then adjuvant chemotherapy, for a fixed time, for treating possible hidden foci of metastasis and thus achieve total control of the disease. What made this concept possible is the selective characteristic of the technique and its high rate of objective response [4,6,13-15]. Although it is reported that the quality of life in patients undergoing traditional chemotherapy treatment is satisfactory, the presence of side effects due to continuous drug therapy is an important factor [9].
Electrochemotherapy has been showing robust results in medicine for several types of tumors and new approaches, such as the one presented in this paper, are promising.

\section{Conclusion}

Electrochemotherapy on bladder proved to be efficient in these two cases, promoting a complete response. Although the results presented were promising, further studies are needed to make this new approach safe and efficient.

\section{References}

1. Rangel MMM, $R$ Pasquale (2017) Electroporation and electrochemotherapy. In: Canine and Feline Geriatric Oncology: Honoring the Human-Animal Bond, JW Sons (Eds.), ( $2^{\text {nd }}$ edn.) Wiley: New Jersey, USA.

2. Mir LM, S Orlowski (1999) Mechanisms of electrochemotherapy. Adv Drug Deliv Rev 35(1): 107-118.

3. Sersa G, D Miklavcic (2008) Electrochemotherapy of tumours. J Vis Exp (22):1038.

4. Cemazar M, Tamzali Y, Sersa G, Tozon N, Mir LM, et al. (2008) Electrochemotherapy in veterinary oncology. J Vet Intern Med 22(4): 826-831.

5. Heller R, R Gilbert, M Jaroszeski (1997) Electrochemotherapy: an emerging drug delivery method for the treatment of cancer. Adv Drug Deliv Rev 26(2-3): 185-197.

6. Aguado Romeo MJ, S Benot López, A Romero Tabares (2017) Electrochemotherapy for the Treatment of Unresectable Locoregionally Advanced Cutaneous Melanoma: A Systematic Review. Actas Dermosifiliogr 108(2): 91-97.

7. Rangel MMM, R Pasquale (2017) Electroporation (EP) and electrochemotherapy (ECT) In: Canine and Feline Geriatric Oncology: Honoring the Human-Animal Bond. In JW Sons (Eds.) ( $2^{\text {nd }}$ Edn.) Wiley: New Jersey, USA, pp. 239-245.

8. Mir LM, Morsli N, Garbay JR, Billard V, Robert C, et al. (2003) Electrochemotherapy: a new treatment of solid tumors. J Exp Clin Cancer Res 22(4 Suppl): 145-148.

9. Fulkerson CM, DW Knapp (2015) Management of transitional cell carcinoma of the urinary bladder in dogs: a review. Vet J 205(2): 217225.

10. Gothelf A, L Mir, J Gehl (2003) Electrochemotherapy: results of cancer treatment using enhanced delivery of bleomycin by electroporation. Cancer Treat Rev 29(5): 371-387.

11. Mir LM (2006) Standard operating procedures of the electrochemotherapy: Instructions for the use of bleomycin or cisplatin administered either systemically or locally and electric pulses delivered by the Cliniporator $<\sup >\mathrm{TM}</$ sup $>$ by means of invasive or noninvasive electrodes. EJC Supplements 4(11): 14-25.

12. Henry CJ (2003) Management of transitional cell carcinoma. Vet Clin North Am Small Anim Pract 33(3): 597-613.

13. Campana LG, Marconato R, Sieni E, Valpione S, Corti L, et al. (2016) [Electrochemotherapy: mechanism of action and clinical results in the locoregional treatment of patients with skin cancers and superficial metastases]. Recenti Prog Med 107(8): 422-433.

14. Guida M, Campana LG, Curatolo P, Strippoli S, Bonadies A, et al. (2016) Local treatment with electrochemotherapy of superficial angiosarcomas: Efficacy and safety results from a multi-institutional retrospective study. J Surg Oncol 114(2): 246-253.

15. Miklavči D, Mali B, Kos B, Heller R, Serša G (2014) Electrochemotherapy: from the drawing board into medical practice. Biomed Eng Online 13(1):29. 
ISSN: 2574-1241

DOI: 10.26717/BJSTR.2018.12.002221

Daniela Ota Hisayasu Suzuki. Biomed J Sci \& Tech Res

(C) (i) This work is licensed under Creative

Submission Link: https://biomedres.us/submit-manuscript.php

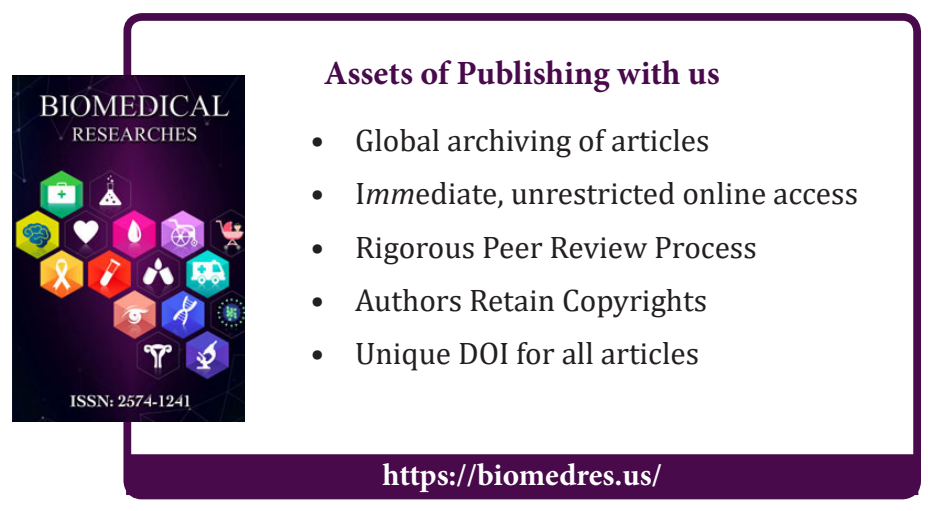

